Article

\title{
Performances and Coating Morphology of a Siloxane-Based Hydrophobic Product Applied in Different Concentrations on a Highly Porous Stone
}

\author{
Mariateresa Lettieri * and Maurizio Masieri \\ Institute of Archaeological Heritage-Monuments and Sites, CNR-IBAM, Prov.le Lecce-Monteroni, 73100 Lecce, \\ Italy; maurizio.masieri@cnr.it \\ * Correspondence: mt.lettieri@ibam.cnr.it; Tel.: +39-0832-422-219
}

Academic Editor: Alessandro Lavacchi

Received: 19 September 2016; Accepted: 9 November 2016; Published: 13 November 2016

\begin{abstract}
Many polymers, able to confer a hydrophobicity to treated surfaces, have been proposed for the restoration and conservation of civil and monumental buildings. Polysiloxanes, and their precursors, the silanes, have been frequently employed for stone protection. To avoid decay of the treated surfaces, the effectiveness and harmlessness of the treatment need to be carefully evaluated before application in the field. In this study, a commercial alkyl-siloxane was tested as a protective treatment on a highly porous stone, starting from water solutions with different contents of the product. The treatments have been devised to try to balance the requirements and the sustainability of the conservative actions. Sustainability, in terms of costs and environmental impact, is regarded as a key factor in the 21st century. Morphological observations of the stone surface, static contact angle and colour measurements, water vapour transmission test, and tests of water absorption were carried out to characterize the untreated and treated stones. A concentration below the minimum level suggested by the manufacturer was still able to act as a good barrier against water. More concentrated solutions produced polymer accumulation and coatings with extended cracks. The properties of the treated stone were affected by the presence of cracks in the coating.
\end{abstract}

Keywords: stone protection; siloxanes; hydrophobic coating; ESEM-EDS; permeability to water vapour; water absorption; contact sponge test

\section{Introduction}

During the last few decades, great attention has been devoted to the restoration and conservation of buildings, especially in the case of monuments and historic built heritage, which are perceived as having cultural value and are potential tourist attractions.

Stone materials used in monuments and buildings generally deteriorate under environmental conditions. The penetration of water through the exposed surfaces is one of the main causes of degradation and damage [1]. The highly porous materials, which are able to absorb larger amounts of water, usually suffer from faster degradation [2]. To limit the ingress of water-and, consequently, to minimize the decay phenomena-suitable preservation remedies are used. The application of coatings, to stop the liquid water entry and let it escape as vapour, is the preferred solution.

Over the years, many polymers, able to confer a hydrophobic character to treated surfaces have been proposed [3-5]. These materials most often are obtained from acrylic, fluorinated, and silicon-based monomers. Among them, polysiloxanes, and their precursors, the silanes, have been frequently used [6-10] and have also recently been proposed as nano-composites by introducing nano-particles of inorganic oxides into hybrid siloxane or silicone polymers [11-15].

However, while some treatments have given good results, others have altered the properties of the stone [16], leading to decay or accelerated degradation processes. For this reason, nowadays, 
the effectiveness and harmlessness of the treatment are carefully evaluated and monitored by in situ investigations [17-20]. In addition, the sustainability of the treatments, in terms of costs and environmental impact, has become a key consideration in the 21st century and it is taken into account when selecting the most appropriate conservation solution.

Starting from these considerations, this study deals with the application of hydrophobic coatings on a highly porous stone widely employed in southeastern Italy, but representative of building materials in many regions of the Mediterranean basin. A siloxane-based product requiring dilution in water was selected, to try and fulfil the requirement of low environmental impact. Different quantities of the product were investigated to find the minimum amount able to provide a suitable hydrophobicity to the tested surfaces.

Preliminary tests verified acceptable colour changes and hydrophobicity of the surfaces after the treatments. Then, investigations of the morphological features of the surfaces were carried out, since as described in the literature, the treatments that give the best results in the protection against water are not those that penetrate deeper into the stone material, but those that adapt their morphology and coat crystals as a film [21,22]. Finally, the variations in some properties (water vapour transport and water absorption) of the treated stone samples were examined.

The obtained results highlighted that the application of higher quantities of the product did not yield the best performances. In addition, the properties of the treated stone were strongly dependent on the characteristics of the coating.

\section{Materials and Methods}

\subsection{Materials}

A commercial product, consisting of organic-modified alkyl-siloxanes having a low molecular weight (trade mark: VP 1805), was investigated. This material (WR) is able to generate hydrophobic coatings and is suggested for the protection of mineral building materials and for stone conservation. As reported in the technical sheet, a dilution with water is necessary before use. Solutions from $5 \%$ to $20 \% \mathrm{w} / \mathrm{w}$ are suggested. No additional information on the amount to apply is given.

The WR product was tested on a highly porous calcarenite, named "Lecce stone". This stone has been widely employed for a long time, as a construction material in southeastern Italy and it is typical of the baroque monuments and buildings of the region. Calcite is its principal constituent, along with very small quantities of clay and other non-carbonate minerals $[23,24]$. "Lecce stone" has a very high porosity, usually ranging from $30 \%$ to $45 \%$ [25-27], and has a unimodal porosity distribution. In our case, the used samples exhibited a porosity of $42 \%$, with pore sizes mainly between 0.3 and $10 \mu \mathrm{m}$, as analysed by mercury-intrusion porosimetry [28]. Due to its characteristics, "Lecce stone" can be considered as representative of the porous materials used for historic and civil buildings in many countries of the Mediterranean basin.

\subsection{Treatments}

Prismatic stone specimens, with dimensions of $5 \times 5 \times 1 \mathrm{~cm}^{3}$ and $5 \times 5 \times 2 \mathrm{~cm}^{3}$, were cut by a saw from a quarry block. According to the UNI10921 standard protocol [29], the samples were smoothed with abrasive paper (180-grit silicon carbide), cleaned with a soft brush, and washed with deionised water in order to remove dust deposits. The stone specimens were completely dried in an oven at $60^{\circ} \mathrm{C}$, until the dry weight was achieved, and stored in a desiccator with silica gel (relative humidity (R.H.) $=15 \%$ ) at $23 \pm 2{ }^{\circ} \mathrm{C}$.

Before the application of the product, the stone specimens were conditioned in equilibrium with the surrounding environment ( $24 \mathrm{~h}$ in the laboratory, at $23 \pm 2{ }^{\circ} \mathrm{C}$ and $45 \pm 5 \%$ R.H.).

The treatments were performed, on 5 specimens of each dimension, by brush, to simulate the methodology of application more commonly used in field conditions. Only one $5 \times 5 \mathrm{~cm}^{2}$ side of each specimen was treated. 
As previously reported, dilution of the WR in water was necessary. Solutions containing $5 \%, 10 \%$, and $20 \% \mathrm{w} / \mathrm{w}$ were prepared and applied. Also solutions with $2.5 \%$ and $40 \% \mathrm{w} / \mathrm{w}$ of product-beyond the recommended range of dilution-were also proposed for the treatments. Each solution was prepared immediately before use, by adding the proper quantity of pure product into $5 \mathrm{~g}$ of water. For each specimen, the application of $1 \mathrm{~kg} / \mathrm{m}^{2}$ of the final solution was planned and the quantity used was controlled by weight measurements.

It is worth mentioning that the application of the solution at $20 \% \mathrm{w} / \mathrm{w}$ was not feasible in the selected dose, that is, $1 \mathrm{~kg} / \mathrm{m}^{2}$. Less than a third of this quantity saturated the superficial layer of the stone, thus hindering any further absorption. Furthermore, it was impossible to prepare the solution at $40 \% \mathrm{w} / \mathrm{w}$, because a fast condensation of the polymer (with precipitate formation) took place just a few seconds after mixing with water. Therefore, the solutions at $20 \%$ and $40 \% \mathrm{w} / \mathrm{w}$ were not further investigated in this study.

Details about the treatments are listed in Table 1.

Table 1. Nomenclature of the treated samples and details of the treatments.

\begin{tabular}{cccc}
\hline Samples & WR Concentration [w/w \%] & Applied Solution $[\mathbf{g}]$ & Treated Surface $\left[\mathbf{c m}^{\mathbf{2}}\right.$ Per Specimen] \\
\hline $\mathrm{T}_{2.5}$ & 2.5 & 2.5 & 25 \\
$\mathrm{~T}_{5}$ & 5 & 2.5 & 25 \\
$\mathrm{~T}_{10}$ & 10 & 2.5 & 25 \\
$\mathrm{~T}_{20}$ & 20 & 0.8 & 25 \\
$\mathrm{~T}_{40}$ & 40 & - & - \\
\hline
\end{tabular}

In order to allow both the solvent evaporation and the completion of condensation reactions, after the application of the solutions, all the specimens were kept in the laboratory at $23 \pm 2{ }^{\circ} \mathrm{C}$ and $45 \pm 5 \%$ R.H. for 30 days, and then they were dried in the oven at $60^{\circ} \mathrm{C}$ until the weight stabilization was achieved; the stabilization was controlled by periodical measurements of weight.

\subsection{Techniques and Methods of Analysis}

Colour and contact angle measurements, morphological observations of the stone surface, water vapour transmission test, and tests of water absorption were performed to characterize the untreated stone material. The same investigations were repeated after each treatment.

All weight measurements were registered using an analytical balance (Model BP 2215, Sartorius AG, Göttingen, Germany) with an accuracy of $\pm 0.1 \mathrm{mg}$.

During the preparation of the specimens, the treatments, and the tests, the environmental conditions were monitored by means of a thermo-hygrometer (Mod. EMR812HGN, Oregon Scientific, Kowloon, Hong Kong). It can collect temperature data from $-50{ }^{\circ} \mathrm{C}$ to $70{ }^{\circ} \mathrm{C}$ (with a resolution of $0.1{ }^{\circ} \mathrm{C}$ ) and relative humidity data in the range $2 \%-98 \%$ (with resolution of $\pm 1 \%$ ).

\subsubsection{Preliminary Tests: Static Contact Angle and Colour Measurements}

Before and after the protective treatments, colour and water-stone static contact angle measurements were performed on the stone surfaces. Colour measurements [30] were performed with a Minolta Chroma Meter CR300 tristimulus colorimeter (Konica Minolta Inc., Tokyo, Japan), using CIE Standard illuminant $C$. Ten measurements were performed on each specimen and the colorimeter was recalibrated to a calibration plate at the start of each measurement session. The colour changes $\left(\Delta E^{*} \mathrm{ab}\right)$ were calculated through the $L^{*} a^{*} b^{*}$ (CIE 1976) system, using the following formula:

$$
\Delta E_{\mathrm{ab}}^{*}=\left[\left(\Delta L^{*}\right)^{2}+\left(\Delta a^{*}\right)^{2}+\left(\Delta b^{*}\right)^{2}\right]^{1 / 2}
$$

where $L^{*}$ is the lightness/darkness coordinate, $a^{*}$ the red/green coordinate $\left(+a^{*}\right.$ indicating red and $-a^{*}$ green), and $b^{*}$ the yellow/blue coordinate $\left(+b^{*}\right.$ indicating yellow and $-b^{*}$ blue). 
Water-stone static contact angle measurements [31] were carried out using a Costech apparatus (Costech International S.p.A., Cernusco sul Naviglio, Milan, Italy). For each specimen, 30 micro-drops of deionised water were deposited with a syringe on different positions of the surface. The shape of the drop was recorded with a camera and its contact angle was calculated by means of the "anglometer 2.0" software (Costech International S.p.A., Cernusco sul Naviglio, Milan, Italy). The water-stone static contact angle was used as indirect evidence of a hydrophobic layer on the surface, since the contact angle cannot be evaluated on the untreated "Lecce stone". Due to intrinsic characteristics of this material, the water absorption is very high and rapid and the drops of water do not remain on the surface [32]. The mechanisms behind the hydrophobic character of the coatings were not investigated in this study.

\subsubsection{ESEM-EDS Analyses}

The morphological features of both the untreated and treated stone surfaces were investigated by an Environmental Scanning Electron Microscope (ESEM, Mod. Philips XL30, FEI Company, Eindhoven, The Netherlands). The observations were carried out in low-vacuum mode (0.6 Torr, $25 \mathrm{kV}$ ). Both secondary (GSE) and backscattered (BSE) electron detectors were used. Magnifications not over $1500 \times$ were set, because surface charging occurred at higher values. The observations through ESEM were performed mainly to search for features of the coatings (such as cracks, bubbles, or other defects) able to influence the behaviour of the stone-coating system in the presence of vapour or liquid water.

Energy-Dispersive X-ray Spectroscopy (EDS) coupled to the ESEM microscope, was applied to detect the presence of $\mathrm{Si}$ on the stone surface where the coating was not clearly visible. Qualitative/quantitative analyses were carried out acquiring EDS spectra on spots (live time $60 \mathrm{~s}$ ).

\subsubsection{Water Vapour Permeability Test}

The water vapour transport properties of the stone material (untreated or treated) were evaluated at $20^{\circ} \mathrm{C}$ by vapour transmission test on the specimens with demensions of $5 \times 5 \times 1 \mathrm{~cm}^{3}$. Each sample was employed to cover a chamber containing $10 \mathrm{~mL}$ of deionised water. PVC containers (Figure 1), properly sealed to force water vapour to diffuse through a central circular surface, were used. The filled containers were placed into desiccators with silica gel and stored in a climatic chamber (Mod. UY 600, ACS Angelantoni Climatic Systems, Massa Martana, Perugia, Italy) at $20^{\circ} \mathrm{C}$.

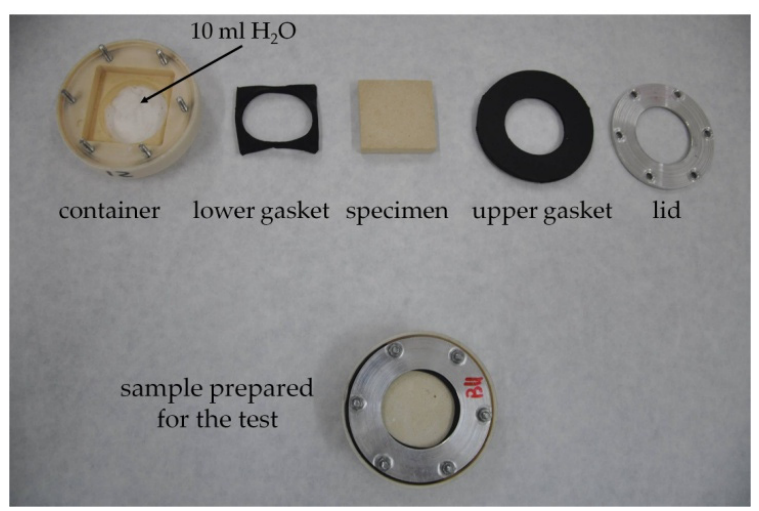

Figure 1. Set-up for water vapour permeability test.

Weight measurements were carried out every $24 \mathrm{~h}$ in order to determine the rate of vapour transport through the sample from the water (in the container the R.H. is close to $100 \%$ ) to the controlled atmosphere of the desiccator (R.H. 15\%, $1 \mathrm{~atm}$ ).

The water vapour flow rate $(G)$ was calculated as the slope of the curve showing the cumulative mass decrease versus time. 
The water vapour transmission rate (WVTR) was evaluated as the mass of water vapour passing through the surface unit in the unit time $(24 \mathrm{~h})$. This parameter is referred to as permeability in [33]. The following equation was used:

$$
\operatorname{WVTR}=\Delta M /(t \times A)
$$

where $\Delta M$ is weight change in the steady state (expressed in $\mathrm{g}$ ), $A$ is the exposed area to water vapour (in $\mathrm{m}^{2}$ ) and $\mathrm{t}$ is the unit time $\left(24 \mathrm{~h}\right.$ ). The exposed area was $0.001611 \mathrm{~m}^{2}$.

Finally, the reduction of the vapour permeability (RVP) was quantified as follows [34]:

$$
\mathrm{RVP} \%=\left[\left(\Delta M_{\mathrm{u}}-\Delta M_{\mathrm{x}}\right) / \Delta M_{\mathrm{u}}\right] \times 100
$$

where $\Delta M_{\mathrm{u}}$ is the weight change in the steady state for the untreated sample, and $\Delta M_{\mathrm{x}}$ is the same parameter calculated for the treated sample.

In all these cases, the $\Delta M$ used was the average of three consecutive values of the daily difference in weight.

\subsubsection{Capillary Water Absorption Test}

The capillarity water absorption test [35] was performed on the stone specimens measuring $5 \times 5 \times 2 \mathrm{~cm}^{3}$. The weight measurements during the absorption were taken at $2.5 \mathrm{~min}, 5 \mathrm{~min}, 7.5 \mathrm{~min}$, $10 \mathrm{~min}, 20 \mathrm{~min}, 30 \mathrm{~min}, 1 \mathrm{~h}, 2 \mathrm{~h}, 3 \mathrm{~h}, 4 \mathrm{~h}, 5 \mathrm{~h}, 6 \mathrm{~h}, 7 \mathrm{~h}, 8 \mathrm{~h}$, and $24 \mathrm{~h}$.

The amount of absorbed water $(Q)$ was calculated as follows:

$$
Q_{\mathrm{i}}=\left(w_{\mathrm{i}}-w_{0}\right) / A
$$

where $w_{\mathrm{i}}$ and $w_{0}$ are the weight of the sample at time $t_{\mathrm{i}}$ and $t_{0}$, respectively, and $A$ is the area exposed to water.

$Q_{\mathrm{i}}$ values were plotted versus the square root of time, and the capillarity water absorption coefficient (AC), representing the slope of the straight part of the absorption curve, was calculated by linear regression.

\subsection{5. "Contact Sponge" Test}

The water absorption was also investigated by the contact sponge test $[36,37]$ to simulate a procedure feasible in the field. The test was performed on either the samples of $5 \times 5 \times 2 \mathrm{~cm}^{3}$ or $5 \times 5 \times 1 \mathrm{~cm}^{3}$, to control the behaviour of all the specimens.

For the "contact sponge" test, a Petri dish, $3.5 \mathrm{~cm}$ in diameter, containing a disc-shaped sponge (area of $9.29 \mathrm{~cm}^{2}$ ) was used. All the tests were performed on specimens dried $24 \mathrm{~h}$ in oven at $60^{\circ} \mathrm{C}$ and stored $24 \mathrm{~h}$ in laboratory conditions $\left(23 \pm 2{ }^{\circ} \mathrm{C}\right.$ and $45 \pm 5 \%$ R.H. $)$.

Preliminary experiments were carried out to establish the volume of water appropriate for the test. The moist sponge was soaked with water and manually pressed against the specimen, which was placed vertically to simulate a small part of a wall. The maximum pressure, restricted by the contact between the dish's borders and the surface, was applied. In this way, the whole surface of the sponge touched the stone, since the wet sponge was only $1 \mathrm{~mm}$ thicker than the Petri dish. The test was carried out by using different quantities of water; 2.50, 2.25, 2.00, 1.75, and $1.50 \mathrm{~mL}$. Water dripped from the sponge pressed against the treated surfaces when more than $1.50 \mathrm{~mL}$ was used. This volume (i.e., $1.50 \mathrm{~mL}$ ), thus, was chosen for all the tests.

A further screening carried out on the untreated stone was aimed at selecting the length of the test. The Petri dish and the sponge inside were weighed after the addition of water and after $15 \mathrm{~s}$ of contact with the surfaces under investigation. At the end of the test, the stone specimens were dried as previously described ( $24 \mathrm{~h}$ in an oven at $60^{\circ} \mathrm{C}$ followed by $24 \mathrm{~h}$ at $23 \pm 2{ }^{\circ} \mathrm{C}$ and $45 \pm 5 \%$ R.H.).

The water absorption was calculated as:

$$
\mathrm{WA}=\left(m_{\mathrm{i}}-m_{\mathrm{f}}\right) /(A \times t)
$$


where $m_{\mathrm{i}}$ is the initial weight of the sponge soaked with water, $m_{\mathrm{f}}$ is the weight of the sponge after the contact, $A$ is the area of the sponge, and $t$ is the contact time.

The same procedure was repeated with increasing time of contact; 30, 45, 60, 90, $120 \mathrm{~s}$. As discussed in Section 3.4, the maximum value of WA was achieved in $1 \mathrm{~min}$. Therefore, to compare the behaviour of the untreated and treated stone specimens, only the contact time of 1 min was tested.

\section{Results and Discussion}

\subsection{Preliminary Tests: Colour Variations and Superficial Hydrophobicity}

Colour differences and water-stone static contact angle determined on the untreated and treated stone samples are reported in Table 2.

Table 2. Colour difference ( $\Delta E_{\mathrm{ab}}^{*}$ ) and water-stone static contact angle (c.a.), with the related maximum deviation, before and after the treatments.

\begin{tabular}{ccc}
\hline Samples & $\boldsymbol{\Delta} \boldsymbol{E}_{\mathbf{a b}}^{*}$ & c.a. $\left[^{\circ}\right]$ \\
\hline Untreated & - & Not determinable \\
$\mathrm{T}_{2.5}$ & 0.76 & $145 \pm 2$ \\
$\mathrm{~T}_{5}$ & 1.55 & $147 \pm 3$ \\
$\mathrm{~T}_{10}$ & 2.55 & $147 \pm 2$ \\
$\mathrm{~T}_{20}$ & 2.00 & $149 \pm 2$ \\
\hline
\end{tabular}

Colour changes increased as the concentration of the applied solution increased, but always remained acceptable. A lower $\Delta E^{*}$ ab was measured for the $\mathrm{T}_{20}$ samples, in comparison to the $\mathrm{T}_{10}$; this behaviour can be ascribed to the low amount of solution applied on the $\mathrm{T}_{20}$ specimens (see Table 1). High hydrophobicity was obtained after the treatments, irrespective of the solution concentration.

Comparable results were found in a previous study [25], after the application of the same solutions with WR on several stone building materials with porosities from $27 \%$ to $45 \%$.

\subsection{Morphological Characteristics and Elemental Microanalysis of the Coatings}

The morphological appearance of the untreated stone surfaces from the ESEM observation is shown in Figure 2a. The treatment with the solution at $2.5 \% \mathrm{w} / \mathrm{w}$ did not change the characteristics of the stone; in fact, it was not possible to perceive a coating on these surfaces even with high magnification (Figure 2b).

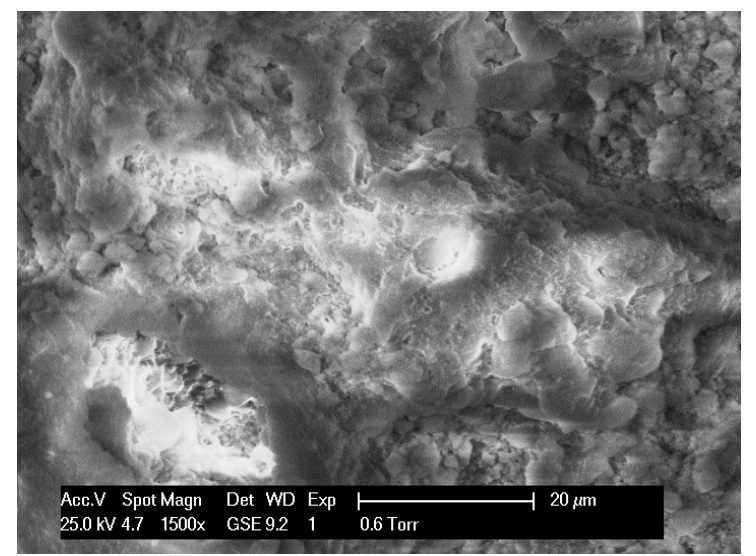

(a)

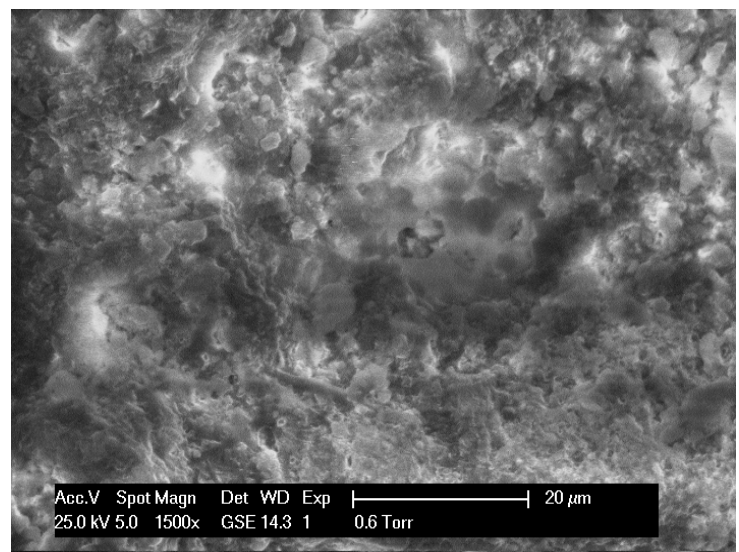

(b)

Figure 2. ESEM images: (a) Untreated stone surface; (b) Surface of $\mathrm{T}_{2.5}$. 
A similar result was found for the $\mathrm{T}_{5}$ samples, where the coating was not clearly recognizable (Figure 3a). In this case, however, the surface seemed to be smoother than the untreated stone. This effect was more evident at higher magnifications. In addition, sporadic micro-cracks (highlighted in Figure 3b) occurred in the flat areas.

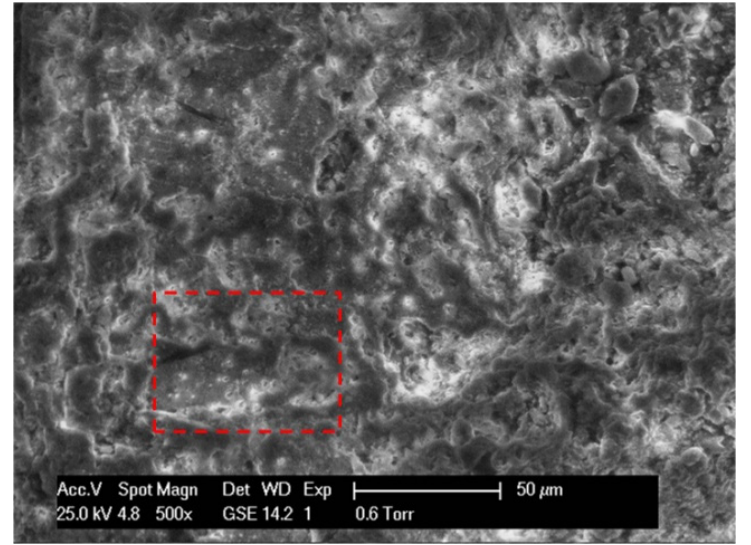

(a)

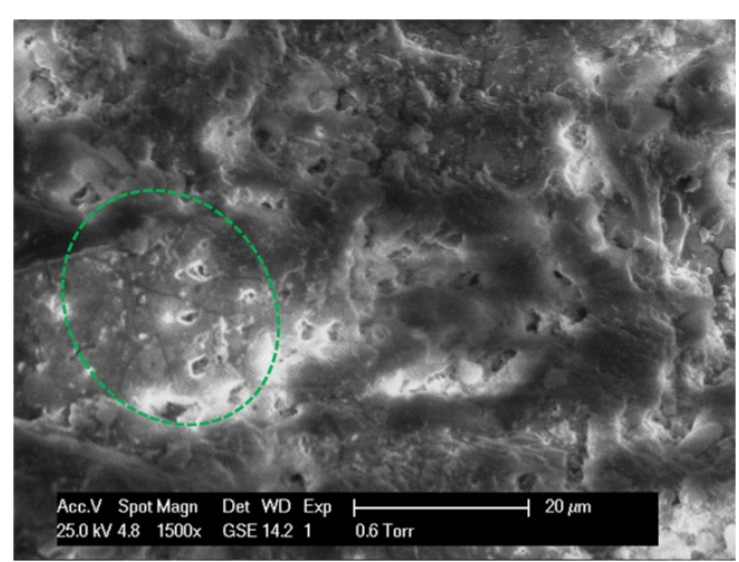

(b)

Figure 3. ESEM images: (a) Surface of $\mathrm{T}_{5}$; (b) Area indicated in (a) at higher magnification.

To prove the occurrence of the coating on these surfaces, Si was searched for using EDS microanalysis. This element can be used as a marker, since WR is a siloxane-based product. Si was already found in very small amounts in untreated Lecce stone (Figure 4a), but increased amounts were expected where the WR was applied. In fact, the higher the concentration of the WR solution, the higher the quantity of Si on the surface (Figure $4 b, c)$. Larger amounts of Si were measured on the $\mathrm{T}_{5}$ samples. In this case, it is probable that the WR product mainly remained on the surface, producing an extremely thin coating. Conversely, in the $\mathrm{T}_{2.5}$ samples, the low concentration of the applied solution enhanced the penetration of WR inside the stone, therefore, lower amounts of Si were found on the surface.

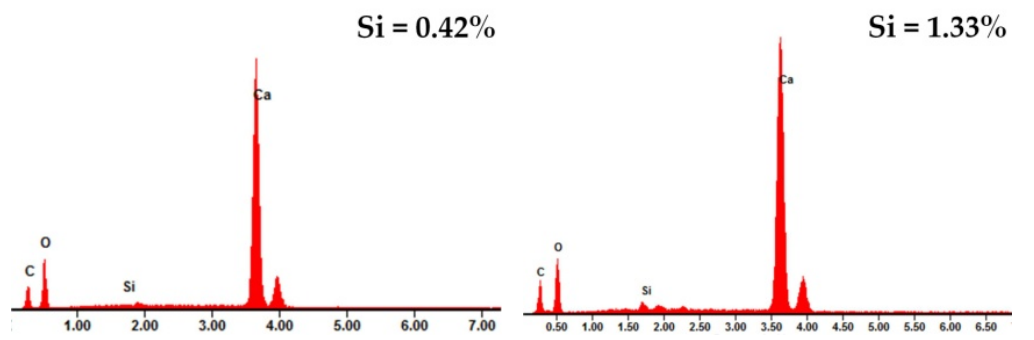

(a)

(b)

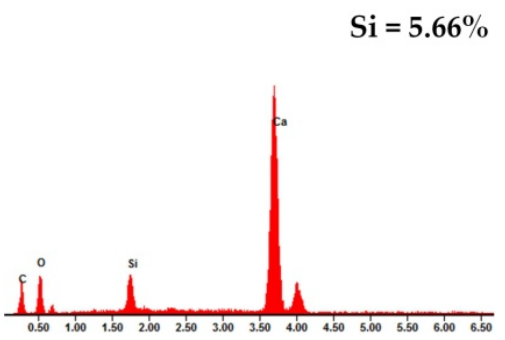

(c)

Figure 4. EDS spectra acquired on (a) the untreated stone, (b) the surface of $\mathrm{T}_{2.5}$ samples, and (c) the surface of $\mathrm{T}_{5}$ samples. In each spectrum, the Si quantification (measured as wt \%) is indicated.

A thick film was obtained from the application of the solution at $10 \%$ and the morphological features of the stone were completely hidden (Figure 5a,b). In this case, an extended network of cracks and fissures, well evidenced by using the BSE detector (Figure 5c,d), affected the coating. The high concentration of the initial solution (i.e., $10 \% \mathrm{w} / \mathrm{w}$ ) limited the penetration of the polymer, with accumulation on the stone surface. On the other hand, the WR in solution at 20\% w/w (i.e., a more concentrated solution), although used in small amounts, quickly saturated the superficial layer of the stone. 


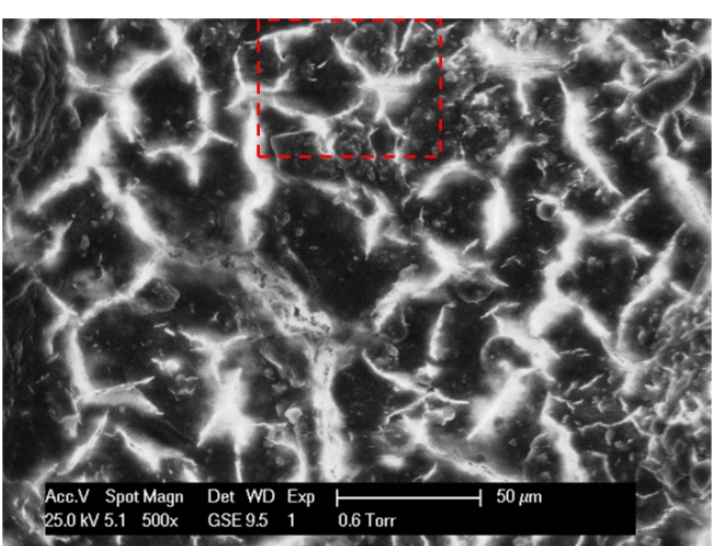

(a)

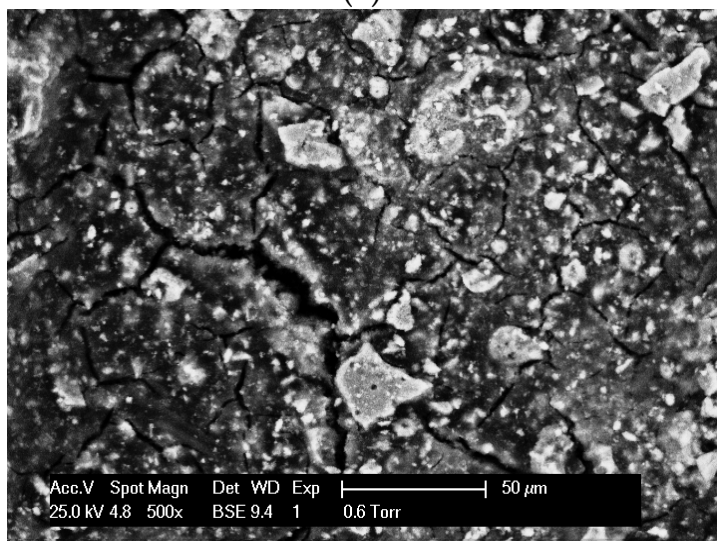

(c)

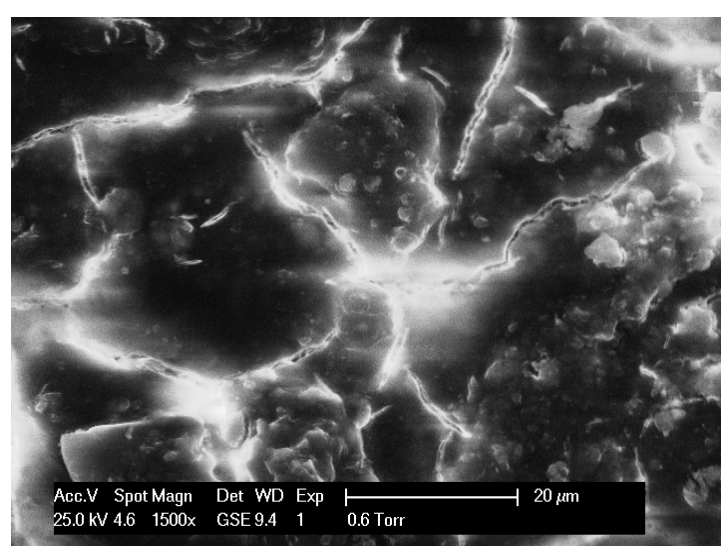

(b)

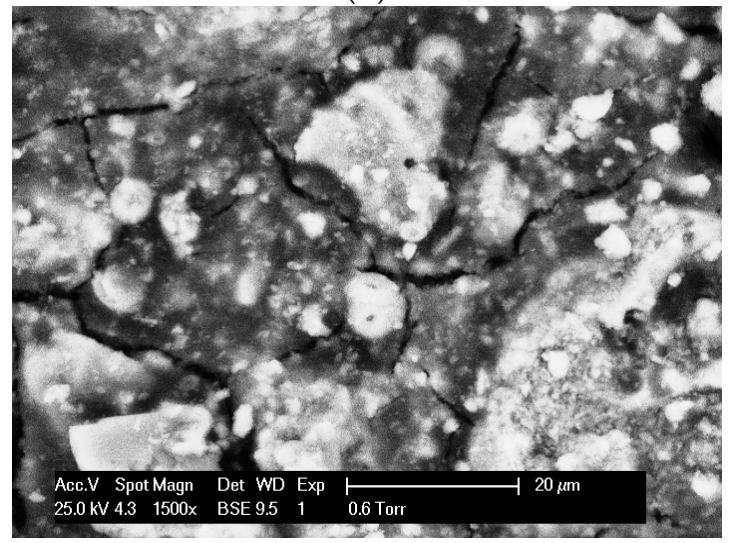

(d)

Figure 5. ESEM images: (a) surface of the $\mathrm{T}_{10}$ sample; (b) area indicated in (a) at higher magnification; using the BSE detector, (c) and (d) were taken in exactly the same areas showed in (a) and (b), respectively.

The presence of fractures in the coating was in accordance with other studies concerning siloxane-based products on stone materials $[22,38,39]$. In fact, products which polymerise by a sol-gel route, such as silanes and siloxanes [5,40], frequently exhibit cracks. These cracks are ascribed to shrinkage phenomena taking place throughout the drying phase [41-43]. In the sol-gel process, shrinking is initiated by evaporation of both solvents and by-products of the condensation step [44]. Then, cracking is generated by the high capillary pressures supported by the gel network during the drying [40]. The amount of water in the ambient atmosphere has been found as a factor influencing the fragmentation of the coating. The lower the amount of water, the more intense the cracking [45]. In our case, the cracking was observed when a smaller amount of water was applied, all other conditions being equal.

\subsection{Water Vapour Transport Properties}

An important aspect to take into account in evaluating the performance (and compatibility in particular) of treatments for stone materials is the changes in water vapour transport properties. The related parameters should be left unchanged by any treatment because reduced permeability may cause water condensation inside the stone. The accumulation of condensed water at the interface between the treated and untreated stone is able to activate the material's decay $[4,46]$.

The mass changes measured throughout the vapour transmission test are plotted in Figure 6. In each case, a linear trend was observed and the steady state was achieved $48 \mathrm{~h}$ after the beginning of the test. 


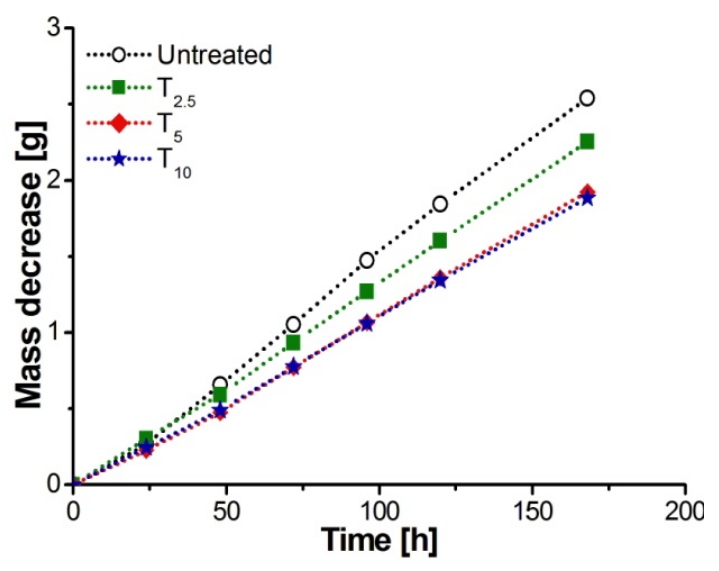

Figure 6. Mass decrease, as a function of time, measured during the water vapour permeability test.

After the application of the WR solutions, reductions were measured for all the water vapour transport parameters (Table 3). The obtained results are comparable to those reported in the literature for siloxane-based coatings on stone materials [15,34,47-49].

Table 3. Water vapour flow rate (G), water vapour transmission rate (WVTR), and reduction of the vapour permeability (RVP). Standard deviations are also reported.

\begin{tabular}{cccc}
\hline Samples & $G\left[(\mathbf{g} / \mathbf{h}) \cdot \mathbf{1 0}^{-\mathbf{3}}\right]$ & WVTR $\left[\mathrm{g} / \mathbf{m}^{\mathbf{2}} \cdot \mathbf{2 4} \mathbf{h}\right]$ & RVP [\%] \\
\hline Untreated & $15.7 \pm 1.1$ & $238 \pm 16$ & - \\
$\mathrm{T}_{2.5}$ & $13.5 \pm 0.4$ & $188 \pm 7$ & -14 \\
$\mathrm{~T}_{5}$ & $11.6 \pm 1.2$ & $168 \pm 11$ & -28 \\
$\mathrm{~T}_{10}$ & $11.3 \pm 0.6$ & $166 \pm 9$ & -34 \\
\hline
\end{tabular}

The permeability decrease, RVP, remained below the threshold of $20 \%$, usually accepted as tolerable [50] (p. 540), only for the $T_{2.5}$ samples.

Water vapour transport decreased as the concentration of the applied WR solution increased. However, an unexpected behaviour was observed in the $\mathrm{T}_{10}$ samples, where values similar to those of the $T_{5}$ samples were found. This behaviour was already observed in similar coatings [51] and attributed not to a higher permeability of the system, but to the formation of small cavities and cracking in the polymer film [9]. The coating on $\mathrm{T}_{10}$ was fractured and it is probable that the cracks facilitated the passage of the vapour through the coating. As a consequence, the reduction in permeability did not further increase, although the applied solution was more concentrated.

\subsection{Water Absorption}

The capillary water absorption curves and the related parameters (i.e., the maximum amount of water absorbed after $24 \mathrm{~h}$ and the capillary absorption coefficient) are reported in Figure 7 and in Table 4, respectively.

Lecce stone is able to absorb large amounts of water by capillary suction [25,52]. In our tests, the untreated samples took approximately $500 \mathrm{mg}$ of water per $\mathrm{cm}^{2}$ in $24 \mathrm{~h}$; around $92 \%$ of this quantity was already gained after $1 \mathrm{~h}$ of exposure. The application of the WR solutions on the stone surfaces strongly affected the capillary water absorption of the stone material, in accordance with the results reported in the literature for similar systems $[13,49]$. All the treatments yielded a marked effect in terms of both the maximum absorbed water and the rate of absorption. The reduction of water up-take was greater in the $T_{5}$ samples, while the lowest ability to limit the water suction was measured in the $\mathrm{T}_{10}$ samples. 


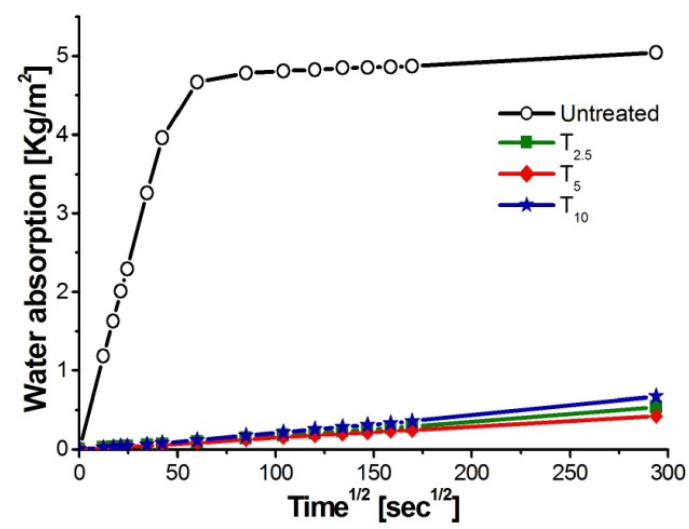

(a)

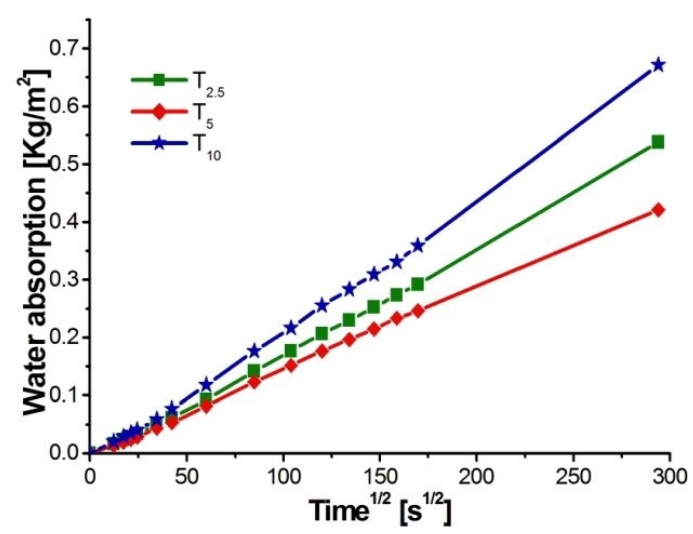

(b)

Figure 7. Capillary water absorption curves: in (a) untreated and treated samples are compared; in (b) only the curves related to the treated samples are reported.

Table 4. Water absorption by capillarity: water absorbed at the end of the test $\left(Q_{24} \mathrm{~h}\right)$ and the capillary absorption coefficient (AC). For each data set the standard deviation is reported.

\begin{tabular}{ccc}
\hline Samples & $\boldsymbol{Q}_{\mathbf{2 4} \mathbf{h}}\left[\mathbf{k g} / \mathbf{m}^{\mathbf{2}}\right]$ & $\mathbf{A C}\left[\left(\mathbf{k g} / \mathbf{m}^{\mathbf{2}} \cdot \mathbf{s}^{\mathbf{- 1 / 2}}\right) \cdot \mathbf{1 0}^{-\mathbf{2}}\right]$ \\
\hline Untreated & $5.04 \pm 0.04$ & $9.34 \pm 1.65$ \\
$\mathrm{~T}_{2.5}$ & $0.54 \pm 0.01$ & $0.15 \pm 0.01$ \\
$\mathrm{~T}_{5}$ & $0.42 \pm 0.06$ & $0.13 \pm 0.01$ \\
$\mathrm{~T}_{10}$ & $0.67 \pm 0.02$ & $0.19 \pm 0.05$ \\
\hline
\end{tabular}

As previously discussed for the water vapour transport, the fractured coating on the $\mathrm{T}_{10}$ samples reduced the ability of the applied coating to act as a barrier against water. As a consequence, the capillary absorption in $\mathrm{T}_{10}$ was higher if compared to that of the $\mathrm{T}_{2.5}$ samples where the coating was thinner but without cracks.

As previously described in Section 2.3.5, a preliminary screening was carried out on the untreated stone in order to select the length of the "contact sponge" test. A progressive increase of WA was measured by up to $1 \mathrm{~min}$ of contact (Figure 8). Longer contact times were not able to cause greater absorptions, but the calculated WA decreased. This result can be the effect of both the saturation of the superficial layers of the stone and an intrinsic limit due to the amount of water used to soak the sponge (i.e., $1.5 \mathrm{~mL}$ ). In fact, after 1 minute about $73 \%$ of the added water was absorbed by the stone. Therefore, $1 \mathrm{~min}$ of contact was adopted for the subsequent tests on the treated surfaces to compare the results obtained in the same test conditions.

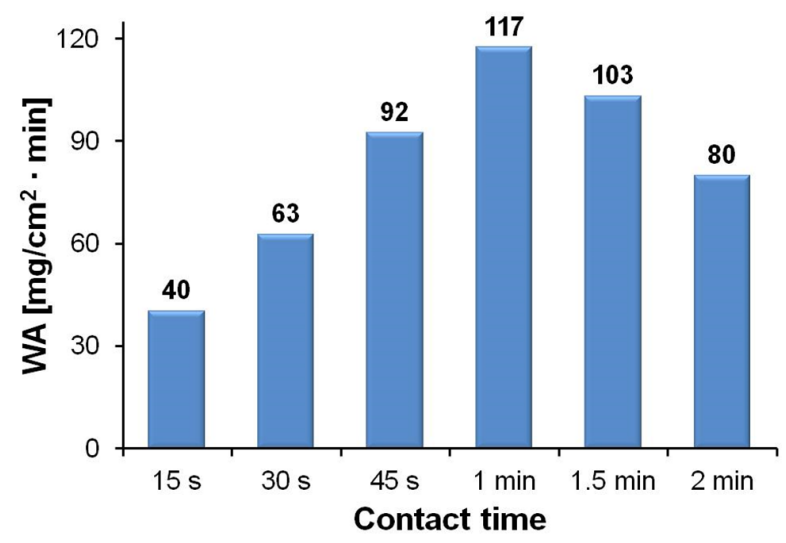

Figure 8. Water absorption measured by the "contact sponge" test on the untreated samples. 
The "contact sponge" test verified variations in the water absorption similar to those observed in the test by capillary rise. The WA values found for the untreated stone were very high and comparable to those reported in the literature [17]. A strong reduction in water up-take was measured after the application of WR (Table 5), with slight differences between the treated samples. The $T_{5}$ specimens exhibited the lowest WA, while the application of the most concentrated solution (at $10 \% \mathrm{w} / \mathrm{w})$ did not further reduce the absorption. On the contrary, for these latter samples, WA values greater than those obtained for $\mathrm{T}_{2.5}$ and $\mathrm{T}_{5}$ were calculated.

The same trend was observed when performing the "contact sponge" test on both the specimens $5 \times 5 \times 2 \mathrm{~cm}^{3}$ and those $5 \times 5 \times 1 \mathrm{~cm}^{3}$ in dimensions.

Table 5. Water absorption (WA) measured by the "contact sponge" test. For each data set the maximum deviation is reported.

\begin{tabular}{ccc}
\hline \multirow{2}{*}{ Samples } & \multicolumn{2}{c}{ WA $\left[\mathbf{m g} / \mathbf{c m}^{\mathbf{2}} \cdot \mathbf{m i n}\right]$} \\
\cline { 2 - 3 } & $\mathbf{1} \mathbf{5} \times \mathbf{5} \times \mathbf{2} \mathbf{~ c m}^{\mathbf{3}}$ & $\mathbf{1} \mathbf{5} \times \mathbf{5} \times \mathbf{1} \mathbf{~ c m}^{\mathbf{3}}$ \\
\hline Untreated & $117.38 \pm 4.44$ & $135.02 \pm 5.58$ \\
$\mathrm{~T}_{2.5}$ & $2.43 \pm 0.32$ & $2.50 \pm 0.04$ \\
$\mathrm{~T}_{5}$ & $1.81 \pm 0.22$ & $1.90 \pm 0.20$ \\
$\mathrm{~T}_{10}$ & $2.69 \pm 0.28$ & $2.86 \pm 0.05$ \\
\hline \multicolumn{3}{c}{}
\end{tabular}

\section{Conclusions}

In this study, a commercial alkyl-siloxane, able to provide hydrophobic coatings, was tested on a highly porous stone. As recommended by the suppliers, the treatments were performed starting from water solutions with different contents of the product. Although the porosity of the stone was elevated, the application of concentrations not higher than $10 \% \mathrm{w} / \mathrm{w}$ was feasible. The treatments provided hydrophobicity to the stone surface and acceptable colour changes. Variations in permeability to water vapour and in absorption of liquid water were found in all the treated samples. Among the applied solutions, the mixture at higher concentration (10\%) did not yield the best performance in terms of protection against water, suggesting that smaller quantities of the product can be effective. In fact, a concentration below the minimum level suggested by the manufacturer was still able to provide coatings that acted as a good barrier against water. When the most concentrated solution was used, polymer accumulation on the stone surface and a coating with extended cracks were obtained. The presence of cracks affected, even if to a low extent, all the evaluated properties of the applied product.

The obtained results suggest that the recommendations given by the suppliers are often generic and sometimes not suitable for specific applications. Therefore, the efficacy of any treatment should always be assessed on the particular material which needs protection, balancing the conservation requirements and the sustainability of the interventions.

Acknowledgments: This study is a part of the Research Project "Protection, consolidation and cleaning of apulian historical stone building materials: testing of low environmental impact products and monitoring of the treatments", supported by the Puglia Funds (FSE-POR Puglia 2006-2013). Thanks are due to A. Calia and L. Matera (CNR-IBAM) for making available the stone specimens and for helping with the sample preparation.

Author Contributions: M. Lettieri conceived and designed the experiments; M. Masieri performed the ESEM-EDS experiments; M. Lettieri performed the permeability and "contact sponge" tests; Chem Spec S.r.l. (Peschiera Borromeo, Milano, Italy) supplied the WR product; M. Lettieri and M. Masieri analyzed the data; M. Lettieri wrote the paper.

Conflicts of Interest: The authors declare no conflict of interest. 


\section{References}

1. Amoroso, G.G.; Fassina, V. Stone Decay and Conservation; Elsevier: Amsterdam, The Netherlands, 1983.

2. Charola, A.E. Salts in the deterioration of porous materials: An overview. J. Am. Inst Conserv. 2000, 39, 327-343. [CrossRef]

3. Horie, C.V. Materials for Conservation: Organic Consolidants, Adhesives and Coatings, 2nd ed.; Butterworth-Heinemann: London, UK, 2010.

4. Doehne, E.; Price, C.A. Stone Conservation: An Overview of Current Research, 2nd ed.; Getty Conservation Institute: Los Angeles, CA, USA, 2010.

5. Sadat-Shojai, M.; Ershad-Langroudi, A. Polymeric coatings for protection of historic monuments: Opportunities and challenges. J. Appl. Polym. Sci. 2009, 112, 2535-2551. [CrossRef]

6. Wheeler, G. Alkoxysilanes and the Consolidation of Stone; Getty Conservation Institute: Los Angeles, CA, USA, 2005. Available online: http://hdl.handle.net/10020/gci_pubs/consolidation_of_stone (accessed on 15 September 2016).

7. Maravelaki-Kalaitzaki, P.; Kallithrakas-Kontos, N.; Agioutantis, Z.; Maurigiannakis, S.; Korakaki, D. A comparative study of porous limestones treated with silicon-based strengthening agents. Prog. Org. Coat. 2008, 62, 49-60. [CrossRef]

8. Zielecka, M.; Bujnowska, E. Silicone-containing polymer matrices as protective coatings: Properties and applications. Prog. Org. Coat. 2006, 55, 160-167. [CrossRef]

9. Simionescu, B.; Olaru, M.; Aflori, M.; Doroftei, F. Siloxane-based polymers as protective coatings against $\mathrm{SO}_{2}$ dry deposition. High Perform. Polym. 2011, 23, 326-334. [CrossRef]

10. Esposito, C.C.; Striani, R.; Frigione, M. UV-cured siloxane-modified methacrylic system containing hydroxyapatite as potential protective coating for carbonate stones. Prog. Org. Coat. 2013, 76, 1236-1242. [CrossRef]

11. Manoudis, P.N.; Karapanagiotis, I.; Tsakalof, A.; Zuburtikudis, I.; Panayiotou, C. Superhydrophobic composite films produced on various substrates. Langmuir 2008, 24, 11225-11232. [CrossRef] [PubMed]

12. De Ferri, L.; Lottici, P.P.; Lorenzi, A.; Montenero, A.; Salvioli-Mariani, E. Study of silica nanoparticles-Polysiloxane hydrophobic treatments for stone-based monument protection. J. Cult Herit. 2011, 12, 356-363. [CrossRef]

13. Facio, D.S.; Mosquera, M.J. Simple strategy for producing superhydrophobic nanocomposite coatings in situ on a building substrate. ACS Appl. Mater. Interfaces 2013, 5, 7517-7526. [CrossRef] [PubMed]

14. Lampakis, D.; Manoudis, P.N.; Karapanagiotis, I. Monitoring the polymerization process of Si-based superhydrophobic coatings using Raman spectroscopy. Prog. Org. Coat. 2013, 76, 488-494. [CrossRef]

15. Pino, F.; Fermo, P.; La Russa, M.; Ruffolo, S.; Comite, V.; Baghdachi, J.; Pecchioni, E.; Fratini, F.; Cappelletti, G. Advanced mortar coatings for cultural heritage protection. Durability towards prolonged UV and outdoor exposure. Environ. Sci. Pollut. Res. 2016. [CrossRef] [PubMed]

16. Varas, M.J.; Alvarez de Buergo, M.; Fort, R. The Influence of Past Protective Treatments on the Deterioration of Historic Stone Façades A Case Study. Stud. Conserv. 2007, 52, 110-124. [CrossRef]

17. Calia, A.; Lettieri, M.; Quarta, G.; Laurenzi Tabasso, M.; Mecchi, A.M. Documentation and Assessment of the Most Important Conservation Treatments Carried out on Lecce Stone Monuments in the Last Two Decades. In Proceedings of the 10th International Congress on Deterioration and Conservation of Stone, Stockholm, Sweden, 27 June-2 July 2004; pp. 431-438.

18. Nwaubani, S.O.; Dumbelton, J. A practical approach to in-situ evaluation of surface-treated structures. Constr. Build. Mater. 2001, 15, 199-212. [CrossRef]

19. Pinna, D.; Salvadori, B.; Galeotti, M. Monitoring the performance of innovative and traditional biocides mixed with consolidants and water-repellents for the prevention of biological growth on stone. Sci. Total Environ. 2012, 423, 132-141. [CrossRef] [PubMed]

20. Perez, E.N.; Alvarez de Buergo, M.; Bustamante, R. Effects of conservation interventions on the archaeological Roman site of Merida (Spain). Advance of research. Procedia Chem. 2013, 8, 269-278.

21. Alvarez de Buergo Ballester, M.; Fort González, R. Basic methodology for the assessment and selection of water-repellent treatments applied on carbonatic materials. Prog. Org. Coat. 2001, 43, 258-266. [CrossRef]

22. Alvarez de Buergo Ballester, M.; Fort González, R.; Gomez-Heras, M. Contributions of scanning electron microscopy to the assessment of the effectiveness of stone conservation treatments. Scanning 2004, 26, 41-47. 
23. Calia, A.; Mecchi, A.M.; Luprano, V.A.M.; Rubino, G.; Rota, P. Microseismic tests in the analysis and characterization of high porosity stone materials. In Proceedings of the 6th International Conference on Non-Destructive Testing and Microanalysis for the Diagnostics and Conservation of the Cultural and Environmental Heritage, Rome, Italy, 17-20 May 1999; pp. 147-162.

24. Bugani, S.; Camaiti, M.; Morselli, L.; Van de Casteele, E.; Janssens, K. Investigating morphological changes in treated vs. untreated stone building materials by X-ray micro-CT. Anal. Bioanal. Chem. 2008, 391, 1343-1350. [CrossRef] [PubMed]

25. Calia, A.; Lettieri, M.; Matera, L.; Sileo, M. The assessment of protection treatments on highly porous stones with relation to the sustainability of the interventions on the historical built heritage. In Proceedings of La Conservazione del Patrimonio Architettonico All'aperto: Superfici, Strutture, Finiture e Contesti; Biscontin, G., Driussi, G., Eds.; Edizioni Arcadia Ricerche: Marghera-Venezia, Italy, 2012; pp. 477-487. (In Italian)

26. Licciulli, A.; Calia, A.; Lettieri, M.; Diso, D.; Masieri, M.; Franza, S.; Amadelli, R.; Casarano, G. Photocatalytic $\mathrm{TiO}_{2}$ coatings on limestone. J. Sol-Gel Sci. Technol. 2011, 60, 437-444. [CrossRef]

27. Licchelli, M.; Malagodi, M.; Weththimuni, M.L.; Zanchi, C. Water-repellent properties of fluoroelastomers on a very porous stone: Effect of the application procedure. Prog. Org. Coat. 2013, 76, 495-503. [CrossRef]

28. Lettieri, M.; Calia, A.; Licciulli, A.; Marquardt, A.E.; Phaneuf, R.J. Nanostructured $\mathrm{TiO}_{2}$ for stone coating: Assessing compatibility with basic stone's properties and photocatalytic effectiveness. Bull. Eng. Geol. Environ. 2015. [CrossRef]

29. UNI 10921 Beni Culturali-Materiali Lapidei Naturali ed Artificiali_Prodotti Idrorepellenti-Applicazione su Provini e Determinazione in Laboratorio delle Loro Caratteristiche; Ente Italiano di Normazione: Milan, Italy, 2001. (In Italian)

30. EN 15886 Conservation of Cultural Property_Test Methods-Colour Measurement of Surfaces; CEN (European Committee for Standardization): Brussels, Belgium, 2010.

31. EN 15802 Conservation of Cultural Property-Test Methods-Determination of Static Contact Angle; CEN (European Committee for Standardization): Brussels, Belgium, 2010.

32. Lettieri, M.; Masieri, M. Surface characterization and effectiveness evaluation of anti-graffiti coatings on highly porous stone materials. Appl. Surf. Sci. 2014, 288, 466-477. [CrossRef]

33. NORMAL Rec. 21/85 Permeabilità al Vapor D'acqua; CNR/ICR: Rome, Italy, 1985. (In Italian)

34. Karapanagiotis, I.; Pavlou, A.; Manoudis, P.N.; Aifantis, K.E. Water repellent ORMOSIL films for the protection of stone and other materials. Mater. Lett. 2014, 131, 276-279. [CrossRef]

35. EN 15801 Conservation of Cultural Property-Test Methods-Determination of Water Absorption by Capillarity; CEN (European Committee for Standardization): Brussels, Belgium, 2009.

36. UNI 11432 Cultural Heritage-Natural and Artificial Stone-Determination of the Water Absorption by Contact Sponge; Ente Italiano di Normazione: Milan, Italy, 2011.

37. Vandevoorde, D.; Pamplona, M.; Schalm, O.; Vanhellemont, Y.; Cnudde, V.; Verhaeven, E. Contact sponge method: Performance of a promising tool for measuring the initial water absorption. J. Cult. Herit. 2009, 10, 41-47. [CrossRef]

38. Maravelaki-Kalaitzaki, P.; Kallithrakas-Kontos, N.; Korakaki, D.; Agioutantis, Z.; Maurigiannakis, S. Evaluation of silicon-based strengthening agents on porous limestones. Prog. Org. Coat. 2006, 57, 140-148. [CrossRef]

39. Aslanidou, D.; Karapanagiotis, I.; Panayiotou, C. Tuning the wetting properties of siloxane-nanoparticle coatings to induce superhydrophobicity and superoleophobicity for stone protection. Mater. Des. 2016, 108, 736-744. [CrossRef]

40. Mosquera, M.J.; de los Santos, D.M.; Rivas, T.; Sanmartín, P.; Silva, B. New nanomaterials for protecting and consolidating stone. J. Nano Res. 2009, 8, 1-12. [CrossRef]

41. Mosquera, M.; Pozo, J.; Esquivias, L. Stress during drying of two stone consolidants applied in monumental conservation. J. Sol-Gel Sci. Technol. 2003, 26, 1227-1231. [CrossRef]

42. Tesser, E.; Antonelli, F.; Sperni, L.; Ganzerla, R.; Maravelaki, N.P. Study of the stability of siloxane stone strengthening agents. Polym. Degrad. Stab. 2014, 110, 232-240. [CrossRef]

43. Salazar-Hernández, C.; Puy Alquiza, M.J.; Salgado, P.; Cervantes, J. TEOS-colloidal silica-PDMS-OH hybrid formulation used for stone consolidation. Adv. Organomet. Chem. 2010, 24, 481-488. [CrossRef]

44. Zárraga, R.; Cervantes, J.; Salazar-Hernandez, C.; Wheeler, G. Effect of the addition of hydroxyl-terminated polydimethylsiloxane to TEOS-based stone consolidants. J. Cult. Herit. 2010, 11, 138-144. [CrossRef] 
45. Ksinopoulou, E.; Bakolas, A.; Moropoulou, A. Modifying Si-based consolidants through the addition of colloidal nano-particles. Appl. Phys. A 2016, 122. [CrossRef]

46. Calia, A.; Lettieri, M.; Mecchi, A.M.; Quarta, G. The role of the petrophysical characteristics on the durability and conservation of some porous calcarenites from Southern Italy. In Sustainable Use of Traditional Geomaterials in Construction Practice; Prikryl, R., Torok, A., Gomez-Heras, M., Miskovsky, K., Theodoridou, M., Eds.; Geological Society: London, UK, 2015; Special Publications 416.

47. Manoudis, P.N.; Karapanagiotis, I.; Tsakalof, A.; Zuburtikudis, I.; Kolinkeová, B.; Panayiotou, C. Superhydrophobic films for the protection of outdoor cultural heritage assets. Appl. Phys. A 2009, 97, 351-360. [CrossRef]

48. Kapridaki, C.; Maravelaki-Kalaitzaki, P. $\mathrm{TiO}_{2}-\mathrm{SiO}_{2}-\mathrm{PDMS}$ nano-composite hydrophobic coating with self-cleaning properties for marble protection. Prog. Org. Coat. 2013, 76, 400-410. [CrossRef]

49. Tsakalof, A.; Manoudis, P.; Karapanagiotis, I.; Chryssoulakis, I.; Panayiotou, C. Assessment of synthetic polymeric coatings for the protection and preservation of stone monuments. J. Cult. Herit. 2007, 8, 69-72. [CrossRef]

50. Snethlage, R. Stone Conservation. In Stone in Architecture; Siegesmund, S., Snethlage, R., Eds.; Springer: Berlin, Heidelberg, Germnay, 2014; pp. 517-520.

51. Kronlund, D.; Lindén, M.; Smått, J.H. A polydimethylsiloxane coating to minimize weathering effects on granite. Constr. Build. Mater. 2016, 125, 1051-1058. [CrossRef]

52. Pinna, D.; Salvadori, B.; Porcinai, S. Evaluation of the application conditions of artificial protection treatments on salt-laden limestones and marble. Constr. Build. Mater. 2011, 25, 2723-2732. [CrossRef]

(C) 2016 by the authors; licensee MDPI, Basel, Switzerland. This article is an open access article distributed under the terms and conditions of the Creative Commons Attribution (CC-BY) license (http://creativecommons.org/licenses/by/4.0/). 